\title{
Different states, common issues: Moving mountains one service at a time
}

\author{
Suzzanne Freeze ${ }^{\mathrm{a}, *}$, Allison Cohen Hall ${ }^{\mathrm{a}}$, Stacy Collins ${ }^{\mathrm{b}}$, Duane Shumate ${ }^{\mathrm{c}}$, Cindy Thomas ${ }^{\mathrm{a}}$ \\ and Barbara Brent ${ }^{\mathrm{d}}$ \\ a Institute for Community Inclusion/University of Massachusetts, Boston, MA, USA \\ ${ }^{\mathrm{b}}$ Ohio Department of Developmental Disabilities \\ ${ }^{\mathrm{c}}$ Missouri Department of Mental Health - Division of Developmental Disabilities, Jefferson City, MO, USA \\ ${ }^{\mathrm{d}}$ National Association of State Directors of Developmental Disabilities Services, Alexandria, VA, USA
}

Received/Accepted March 2017

\begin{abstract}
.
BACKGROUND: In an ever-evolving landscape, states are working to achieve new levels of integrated employment outcomes. While states have been building supports for more than five decades to meet the needs of their constituents, a different playing field has emerged in recent years. This is a result of new regulations, requests from advocates and families, shifting expectations and fluctuating state budgets.

OBJECTIVE: How are states managing the range of large and small changes needed to update the employment and employment-related service definitions that are offered? How can we ensure connection between employment and other full life outcomes? And most importantly, how can stakeholders establish individual integrated employment as a priority goal?

CONCLUSION: This article describes states' efforts towards employment first goals and outlines more changes that need to be made.
\end{abstract}

Keywords: IDD, SELN, ICI, State data, integrated employment, state systems, CMS HCBS' settings rule, WIOA, state strategies, Olmstead, Missouri, Massachusetts, Ohio, systems change

\section{Introduction}

At the national level, integrated employment has become an important policy priority. Greater expectations are being placed on those charged with delivering employment supports, and disability systems are responding. However, the promise of integrated employment has yet to be realized for individuals with intellectual and developmental disabilities (IDD). The number of individuals supported in integrated employment by state IDD agencies has remained level since 2000, participation in non-work services has grown rapidly, and promising practices for employment supports identified in the research are

\footnotetext{
*Address for correspondence: Suzzanne Freeze, Institute for Community Inclusion/University of Massachusetts, Boston, 100 Morrissey Boulevard, Boston, MA 02125, USA. Tel.: +1 617287 4395; E-mail: Suzzanne.freeze@umb.edu.
}

not widely implemented (Butterworth et al., 2015a). What are the state-level strategies that will change this trajectory?

\subsection{Employment as a national priority}

In recent years, the IDD and broader disability advocacy community began mobilizing around an Employment First vision. This embraces the notion that anyone who wants to work can work, with the right supports and job match, regardless of the severity of their disability.

Employment is culturally and economically critical for providing opportunities to thrive as an individual as well as a community member in our country. State and local efforts, in concert with federal regulations, are being aligned to help individuals develop the means for addressing the limits of living 
in poverty. The U.S. Department of Labor and federal offices that serve people with disabilities are working together to promote Employment First policies (U.S. DOL, no date). At the time of this writing, almost every state has some type of Employment First initiative, policy, or grassroots effort, with 32 states having an official policy or directive (Hoff, 2016). The introduction of Employment First policies has been an important step toward helping people with disabilities participate fully in society, move out of poverty, and become self-sufficient (Butterworth et al., 2015b). Other evidence at the federal level demonstrates that shifts are occurring and represent key drivers in state and local changes:

The Centers for Medicare and Medicaid Services released guidance to the field clarifying their commitment to integrated employment as an outcome of employment-related services under the Home and Community-Based Services waiver, and has issued new rules related to the assessment of communitybased employment settings (Center for Medicaid and Medicaid Services, 2014). While the 2011 bulletin did not constitute new policy, it highlighted opportunities available to increase employment for individuals with disabilities, noted CMS's commitment to the importance of work and provided further clarification of CMS guidance on several core service definitions. The primary changes to the $\S 1915$ (c) Waiver Instructions and Technical Guide addressed in the bulletin are summarized as follows:

- Highlights the importance of competitive work for people with and without disabilities and CMS's goal to promote integrated employment options through the waiver program

- Acknowledges best and promising practices in employment supports, including self-direction and peer support options for employment support

- Clarifies that Ticket to Work Outcome and Milestone payments are not in conflict with payment for Medicaid services rendered because both Ticket to Work and Milestone payments are made for an outcome, not service delivery

- Adds a new core service definition by splitting what had previously been supported employment into two definitions- individual and small group supported employment

- Includes a new service definition for career planning that may be a separate service or rolled into the other employment related service definitions
- Emphasizes the critical role of person centered planning in achieving employment outcomes

- Modifies both the prevocational services and supported employment definitions to clarify that volunteer work and other activities that are not paid, integrated community employment are appropriately described in pre-vocational services, not supported employment services

- Explains that pre-vocational services are not an end point, but are time limited (although no specific limit is given)

- Discusses that self-directed service delivery models can also be used to provide employment supports and describes such models, with individuals hiring their own job coaches and support staff (NASDDDS, 2016).

Notable in the 2011 Bulletin from CMS is the amount of values-based language it contains, such as the investment in person centered planning and pointing out the ways in which Medicaid funds should support opportunities to increase employment outcomes compared to historically segregated options. "Work is a fundamental part of adult life for people with and without disabilities. It provides a sense of purpose, shaping who we are and how we fit into our community." The bulletin continues, "because it is so essential to people's economic self-sufficiency, as well as self-esteem and wellbeing, people with disabilities and older adults with chronic conditions who want to work should be provided the opportunity and support to work competitively within the general workforce in their pursuit of health, wealth and happiness. All individuals, regardless of disability and age, can work - and work optimally with opportunity, training, and support that build on each person's strengths and interests." (NASDDDS, 2016).

In addition to the 2011 CMS Bulletin, the HCBS Final Rule regarding HCBS services, including person centered planning and settings, which took effect in March 2014, creates more clarity in the definitions of home and community-based settings, rather than one based solely on a setting's location, geography, or physical characteristics (CMS, 2014). The rule requires that all HCBS settings must: be integrated within and facilitate access to the community, optimize autonomy and independence, chosen by the individual, and provide an opportunity to work in the community (HCBS Advocacy Coalition, 2015). All states have until March 17, 2019 to meet the new settings requirements. All states were required to submit a transition plan to CMS by March 17, 2015. At the 
time of this writing, several states have an initially approved state transition plan, but only one state, Tennessee, has a final approved transition plan.

In July 2014, the Workforce Innovation and Opportunity Act (WIOA) required that each state's public vocational rehabilitation (VR) agency focus on transition services and pre-employment services, coordinate with the state agency responsible for administering the state Medicaid plan and with state IDD agencies, and focus on the general workforce development system and One-Stop Career Centers (also called American Job Centers). WIOA also puts into place restrictions on the use of sub-minimum wage. (As of 2016), the legislation incorporates a series of steps that individuals aged 24 and younger must go through before being placed in a position that pays less than minimum wage. Steps include: 1 ) pre-employment transition services; 2) determination of ineligibility for VR services or an unsuccessful VR closure; and 3) provision of career counseling and referrals designed to assist individual to achieve competitive integrated employment (Hoff, 2014). Also as of 2016, schools are no longer allowed to contract with organizations to pay individuals sub-minimum wage. WIOA provides a federal definition of "competitive integrated employment" which includes: full-time or part time work at minimum wage or higher; wages and benefits similar to those without disabilities performing the same work; and fully integrated with co-workers without disabilities. The legislation created a WIOA Advisory Committee whose goals are to prepare findings and recommendations for the U.S. Secretary of Labor on: ways to increase competitive integrated employment for people with IDD, including those with significant disabilities, and the use of sub-minimum wage certificates (Mank, 2016).

In multiple states, the U.S. Department of Justice has extended the Olmstead vs. L.C. decision related to the unnecessary segregation of people. As recently as October, 2016, the Department of Justice issued further clarification on the how the ADA's integration mandate and Olmstead should be applied to publiclyfunded employment services. The memo statement clarifies the definition of "most integrated setting" and the importance of informed choice for individuals with disabilities, who have traditionally been steered towards more segregated service options. The memo makes clear that the mandate is extended to both those classes of people currently served in segregated settings, as well as those at risk for segregation. Guidance around access to competitive employment services addresses: individualization of services; intensity and duration of services; and access to integration and necessary supports during non-work hours (U.S. Department of Justice, 2016).

\section{State strategies: How are states responding to this federal context?}

The remainder of this paper shares state-level insights from systems change work. Through the work of the State Employment Leadership Network (SELN) and Rehabilitation Research and the Training Center on Advancing Employment for Individuals with Intellectual and Developmental Disabilities (Center), we highlight three states that are responding to this shifting national context. The purpose of the SELN is to establish a learning community of states interested in improving employment outcomes for persons with intellectual and developmental disabilities, support the development of employment policy and strategy, and increase the number of individuals with developmental disabilities working in the general workforce. The goal of the Rehabilitation Research and Training Center on Advancing Employment for Individuals with Intellectual/Developmental Disabilities is to identify strategies to support state agencies, providers, advocates, individuals and families to make the philosophy of Employment First a reality.

Explored in more detail below, stakeholders in Missouri, Massachusetts, and Ohio are revising employment and employment related services to bridge current requirements and transition to new expectations; establishing individual integrated employment as a priority goal over other segregated outcomes; and rolling out implementation of these changes in sync with other aspects of their systems' work such a new community integration options.

\subsection{How is Ohio's state intellectual and developmental disability (IDD) agency using policy and strategy to address changing rules and expectations on community settings and integrated employment? In what ways do the revision of Medicaid waiver service definitions facilitate these changes?}

After joining the State Employment Leadership Network (SELN) and completing the state strategic employment assessment process, Ohio's Department 
of Developmental Disability (DODD) established the state's 2012 Employment First Executive Order. In combination, these actions were a springboard for recognizing needed changes to the existing service system and represented the public support system's formal acknowledgement of the need for systemswide and coordinated changes. These changes were widely accepted as necessary to ensure that individuals and families can be fully integrated members of their communities. In collaboration with five other key state agencies as well as the Ohio Developmental Disabilities Planning Council (DDPC), Ohio established employment first principles to address strategic questions such as:

- What new or adapted action plans are needed across the state and by which parties?

- How do we continue to bring forward an array of feedback and voices to the systems change process and ensure practices can be taken to scale statewide?

The Executive Order established statewide collaboration and coordination by creating the Employment First Taskforce (EFTF) and Advisory Committee, and made community employment the preferred outcome for individuals with developmental disabilities. The EFTF is charged with expanding community employment opportunities by reducing barriers and aligning state policy.

Through partnership with the EFTF, DODD embarked on an ongoing strategic planning process to ensure the employment first work would be informed by the state's expanding policy needs, reflect new outcome expectations and develop appropriate oversight mechanisms for accountability. The Task Force, through the release of nine recommendations, communicated expectations for statewide systems change. DODD has worked to address and achieve accomplishments for all nine of the recommendations over the last four years.

A significant aspect of DODD's early and initial employment first efforts is the establishment of a productive and ongoing strategic planning cycle, with a particular emphasis on action-oriented results at the state, county and local levels. Key to this work has been the use of a formal, local team structure to help assess the needs of various community employment collaboration areas. All local teams were tasked with completing strategic assessments for systems transformation across a range of applicable need categories. The local team structure was meant to mimic the state's Employment First Task Force in composition and focus. This provided the state level organizations with an opportunity to discuss priority topics and consider the impact on the local level implementers.

DODD continues to support the ongoing systems change work through in person events (conferences, local meetings, county-specific gatherings), smaller workgroup discussions (on an as needed basis) and online tools such as the DODD website and the newly launched Loop Ohio.

The current EFTF work is centered on transitionage youth and implementing Ohio's Employment First Transition Framework. This Framework is a critical component to the Ohio Employment First structure and is intended to address barriers to transition planning and services in order to achieve meaningful adult outcomes. The Framework was developed by stakeholders from multiple agencies to create processes and highlight practices that can be used by all agencies. These common processes assist professionals to plan, prepare, empower, educate, and connect across systems so as to consistently assist youth with disabilities to realize meaningful, community employment and other valued aspects of adult life.

The DODD's Strategic Planning Leadership Group (SPLG) engaged the statewide developmental disabilities community in processes to help set strategic direction, and improve Ohio's system for the next ten years and beyond. Twenty-four representatives from 14 stakeholder organizations, along with representatives from the Ohio Office of Medicaid and DODD, comprised the SPLG. The Group met monthly from November, 2013-November, 2014 to examine trends and issues, conduct in-depth analyses of data, and learn about best practices. In addition, four Open Forums offered opportunities for the SPLG to invite people with disabilities, families, services providers and County Board staff from across Ohio to hear presentations from recognized national leaders. These efforts culminated in 24 Ten-Year Benchmarks and the SPLG continues to meet and consider more recent external influences impacting Ohio's system of supports.

DODD has fully committed to strong partnerships and collaboratively creating a bridge from today's service system to the newly envisioned system of the future. Strategically, a critical areas of systems change is the development of new and different services to communicate outcome expectations related to public funding. A clear tool for conveying this message is through revising current services and adding 
new services which appropriately incentivize integrated services through a new service model based on a system that supports informed choice, community integration, and competitive employment. A distinct goal in this effort is to clarify the expected outcomes for each funded service, ensuring all services are focused on person centered planning and individual outcomes. Instituting services which lead an individual and family members intentionally along a career pathway including desired community integration goals, is of paramount importance.

\subsection{How is Massachusetts addressing the transition from sheltered employment to other day and employment supports?}

In 2010, the Department of Developmental Services (DDS) adopted an Employment First policy. This was followed in November, 2013 by the "Blueprint for Success: Employing Individuals with Intellectual Disabilities in Massachusetts." The Blueprint was developed by DDS in partnership with the Association of Development Disability Providers and The Arc of Massachusetts. Given recent federal policy changes and directives, the Blueprint set forth an aggressive plan to close sheltered workshops and provide supported employment in integrated settings. The key milestones in the plan (referred to as the "Blueprint") included:

- Close the "front door" to sheltered workshops as of January 1, 2014 by ceasing new referrals.

- Close sheltered workshops by June 30, 2015. [Subsequently extended to June 30, 2016].

- Transition participants in sheltered workshop programs to one of the following options: integrated individual or group employment at minimum wage or higher and/or CommunityBased Day Services (CBDS).

- Continue to transition individuals from CBDS to integrated work opportunities that pay minimum wage or higher based on person-centered career plans.

- Gradually phase out group employment settings that pay less than minimum wage.

Massachusetts' Department of Developmental Services committed to funding an 18 month capacity building initiative to strengthen its provider base. Key components included (a) extensive staff training opportunities; (b) support for organizational change strategies through external consultation; (c) a focus on an employment collaborative model to better coordinate job opportunities within the business community; and (d) technical assistance on vocational assessment and person-centered career planning to provider staff and DDS service coordinators. (Massachusetts Blueprint for Success, 2013). An Employment First Implementation Workgroup supports and monitors the implementation of the Blueprint.

A key component of the initiative was its abbreviated timeline to close sheltered workshops, as well as a DDS commitment to continuing the existing level of service as part of the transformation process. While HCBS waiver dollars no longer go towards funding sheltered workshops in Massachusetts, there has been an increase in the numbers of individuals served in community-based day supports (Butterworth et al., 2015a). Stakeholders note that the two main challenges the state faces are: (1) promotion of integrated employment outcomes, and (2) ensuring that community-based day supports are truly community-based, AND serve the intended purpose. CBDS are intended to support an individual on a pathway to employment, provide supplemental support for individuals who are working in the community (e.g. support a person for the hours s/he is not working), and/or as a support for retirement.

In order to address some of these issues, Massachusetts DDS is developing more specific guidance about what services should look like. The state is revamping its quality assurance process to reflect changing expectations and the HCBS waiver "community rule" that describes the standards settings funded by HCBW service must meet in order to be considered in compliance. DDS in partnership with provider representatives is developing an assessment tool that providers can use to review their current service model and develop plans for transforming CBDS service delivery. "Ensuring Excellence in Community-Based Day Supports: A Guide for Service Providers and Staff" was developed for DDS by the Institute for Community Inclusion and provides a framework for the CBDS services transformation efforts.

To support these efforts, the state has identified the need for capacity building through training, technical assistance, and other resources, including peer to peer learning, for providers throughout Massachusetts. The state is also committed to making a financial investment by ensuring funding can support higher staffing ratios that allow for meaningful and purposeful experiences in the community.

While much progress has been made to date, the state has identified several areas where additional 
work is required. These include: support and training for service coordinators to prioritize employment, development of resources and materials for individuals and families, consistent implementation of new policies, procedures, and practices in a decentralized system, and the development of business processes that are integrated and flexible within this evolving system.

\subsection{What changes are occurring in Missouri to intellectual and developmental disability (IDD) agency policy and strategy in relationship to the Supreme Court's Olmstead decision and the Workforce Innovation and Opportunity Act (WIOA) of 2014 ?}

Through the leadership of the Department of Mental Health's Division of Developmental Disabilities, the state of Missouri prioritized outreach activities, capacity building (specifically through individual support plans and available services), and a system of collaborative supports. This work was designed to assist the Division with addressing three key areas:

- Purposeful engagement and support to and for family members of individuals with disabilities

- Acknowledgement of employment competencies as essential to achieving new work and community life goals

- The critical need to use all available resources across public support systems.

Outreach activities were designed to spread a clear and consistent message on the role of employment and community life for Missourians with an intellectual or developmental disability. Through deliberate communications with a variety of audiences the Division has emphasized that working and being a valued member of the community are:

- A fundamental part of everyone's life

- Essential in developing a deeper level of self (identity, confidence, drive, independence)

- Avenues for earning income and building financial assets

- Known to also strengthen physical and mental health

Targeted outreach was used to communicate with: individuals and families, Missouri's community transition teams, community businesses and civic organizations. The Division developed a variety of "tip sheets" and also distributed newsletters and data reports (called "dashboard") to educate readers on the current services and outcomes and new goals for improvement in the future.

A second strategy in Missouri has been to deliberately focus on two particular capacity-building efforts, specifically the development of individual support plans and the paid services available across the state. Service plans communicate priorities at an individual level and provide a Daily Life and Employment Exploratory Questions tool for keeping all involved parties accountable. Addressing this area of the service system allows the Division to guide plan authors and plan implementers in achieving career planning, financial literacy and community life engagement expectations.

Additionally, Missouri is addressing capacity building by ensuring individuals have access to high quality, efficient and effective community-based services through an Individual Support Plan Guide organized by life domains. The available services are being reviewed and scrutinized to ensure individuals receive support to achieve career and life planning goals, build new skills as interests change, ensure a meaningful role in the community and remain personcentered and individual-specific.

The Division has worked to build a robust Employment First culture in Missouri. This foundation supports a wide variety of implementation activities and builds on past efforts with revamped: Disability Benefits 101 tools, person centered plan guidelines, services-related tools, revised memorandums of understanding, and resources from nationally-known promising practices. The Division's engagement in the SELN has boosted access to shared lessons in other states and has enhanced the achievement of certain employment and community life goals.

A third goal for Missouri is specific to a vigorous system of collaborative supports. Through concerted efforts the Division is working with other public systems to ensure individuals and families have access to:

- Early career and community experiences to build exposure and confidence

- A streamlined sequence of services using all available funding sources

- Effective and efficient services at any life stage

- Specific resources for transition planning to move from school to adult life

Missouri has capitalized on partnerships with many organizations to ensure the shared values and goals of employment first are embraced and upheld. 
Ongoing and new committees and groups have been used to provide a forum for discussion and debate to ensure all voices are heard and respected in the change process. The following groups are recognized as having made major time commitments to employment first: ShowMeCareers, WIOA System and Design Team, State Employment Leadership Network, Missouri Interagency Transition Team, Project SEARCH, Association of People Supporting EmploymentFirst, Community Transition Teams, and Regional Transition Networks.

\section{Conclusion}

State and local systems continue to pave the way for more individuals with IDD to experience integrated employment options while building new paths for economic self- sufficiency and meaningful roles in their communities. The profiled states' efforts describe their work and the work of many other SELN member states who remain committed to employment first goals. States must align all relevant policies and practices to best leverage them to increase opportunities for competitive integrated employment. Over a decade ago the SELN along with partners such as the Rehabilitation Research and Training Center on Advancing Employment recognized that systems change at the state, regional, area and local levels is critical for providing the needed structural foundation for achievement of new individual integrated employment outcomes across our country

Additionally, the changes must directly tie back to the key system drivers outlined earlier in partnership with the authoring federal entities. In combination, the systems change generated by these drivers illustrate heightened awareness on the ability of all interested individuals to experience integrated employment earlier, more routinely, over the course of a career path, and without unnecessary delays. The drivers clarify the importance of individuals achieving their employment goals in concert with federal expectations, and not in spite of such influences. State systems must use the available opportunities to determine whether current investments are producing the intended outcomes, and if not, provide the strategic leadership to respond and produce the adaptations necessary to reach intended goals.

\section{Conflict of interest}

The authors have no conflict of interest to report.

\section{References}

Butterworth, J., Winsor, J., Smith, F. A., Migliore, A., Domin, D, Ciulla Timmons, J., \& Hall, A. C. (2015a). StateData: The national report on employment services and outcomes. Boston, MA: University of Massachusetts Boston, Institute for Community Inclusion.

Butterworth, J., Hiersteiner, D., Engler, J., Bershadsky, J., \& Bradley, V. (2015b). National Core Indicators: Data on the current state of employment of adults with IDD and suggestions for policy development. Journal of Vocational Rehabilitation, 42(3), 209-220.

CMS (2014). Home and Community-Based Services. Retrieved from https://www.cms.gov/Newsroom/Media ReleaseDatabase/Fact-sheets/2014-Fact-sheets-items/201401-10-2.html

HCBS Advocacy Coalition (2015). The Medicaid Home and Community Based Services settings rules: What you should know! Retrieved from http://www.aucd.org/docs/policy/HCBS/ HCBS\%20Settings\%20Rules_What $\% 20$ You\%20Should $\% 20$ Know!\%20Final\%20Oct\%2026,\%202016.pdf

Hoff, D. (2016). SELN Working Document. Employment First Resource List.

Hoff, D. (2014). WIA is now WIOA: What the new bill means for people with disabilities. Institute Brief, (31). Boston, MA. Institute for Community Inclusion, University of Massachusetts, Boston. Retrieved from https://www. communityinclusion.org/pdf/IB31_F.pdf

Mank, D. (2016). WIOA (2014) and Competitive Integrated Employment. Department of Labor, January, 2016. Retrieved from http://www.rfwia.org/images/Website_Documents/ Mank/Dept_of_Labor_ACICIEID_WIOA_ACCSES_0116.pdf

Massachusetts Blueprint for Success (2013). Retrieved from http://www.mass.gov/eohhs/docs/dmr/blueprint-forsuccess.pdf

NASDDDS (2016). Three State Experiences: Policy Analysis of Employment Policy and Strategy that Impacts Employment Outcomes and Services for Individuals Served by State Intellectual/Developmental Disabilities (I/DD)Agencies. Unpublished paper.

U.S. Department of Justice (2016). Statement of the Department of Justice on Application of the Integration Mandate of Title II of the Americans with Disabilities Act and Olmstead v. L.C. to State and Local Governments' Employment Service Systems for Individuals with Disabilities. Retrieved from https:// www.ada.gov/olmstead/olmstead_guidance_employment.htm \#_ftnref16

United States Department of Labor, Office of Disability and Employment Policy. (n.d). Employment First. Retrieved from www.dol.gov/odep/topics/employmentfirst.htm 